\title{
Preface: Optimization under uncertainty—costs, risks and revenues Cyrus Derman memorial volume II
}

\author{
Michael N. Katehakis ${ }^{1}$ - Sheldon M. Ross ${ }^{2}$ • Jian Yang ${ }^{3}$
}

Published online: 18 May 2016

C Springer Science+Business Media New York 2016

Optimization under uncertainty refers to scientific methods that are used in many different ways in a wide range of fields including statistics, economics, finance, insurance, psychology, sociology, engineering, operations, management science and information sciences. Cyrus Derman participated and played an important role in the formation of this area with his contributions, his writings and his students; as of March 2016, he has 271 descendants listed at the Mathematics Genealogy Project.

Initially we planned to have a single volume. However, we received so many excellent contributions that it became necessary to have two volumes. This second volume is being published later than we had planned because we continued to receive excellent contributions and we had to extend the publication date.

We would like to express our gratitude to the authors that contributed to this volume. Some of them had the good fortune to know and learn from Cy Derman. This volume would not have been possible without the anonymous contributions of the reviewers. Acknowledgments are due to Andrzej Ruszczyński and Endre Boros for their initial and continual support of the idea to do these volumes. Arthur F. Veinott Jr., Uriel Rothblum and Eugene Feinberg were also sources of support. Katie D'Agosta, the journal's managing editor, worked tirelessly to assist us in all aspects of the work.

Michael N. Katehakis

mnk@rutgers.edu

Sheldon M. Ross

smross@usc.edu

Jian Yang

jyang@business.rutgers.edu

1 Department of Management Science and Information Systems, Rutgers Business School, Newark and New Brunswick, 100 Rockafeller Road, Piscataway, NJ 08854, USA

2 Department of Industrial and Systems Engineering, University of Southern California, 3715 McClintock Avenue, GER 240, Los Angeles, CA 00089-0193, USA

3 Department of Management Science and Information Systems, Rutgers Business School, Newark and New Brunswick, 1 Washington Park, Newark, NJ 07102, USA 